\title{
Sistem Forecasting Keuangan Inventaris Sarana dan Prasarana dengan Metode Naive Approach pada Universitas CIC
}

\author{
Sakti Wibawa ${ }^{1}$, Petrus Sokibi ${ }^{2}$ \\ ${ }^{1,2}$ Fakultas Teknologi Informasi, Universitas Catur Insan Cendekia, Jl. Kesambi No. 202, Cirebon, 45133 \\ e-mail: ${ }^{1}$ sakti-ti16@ std.cic.ac.id, ${ }^{2}$ petrus.sokibi@cic.ac.id \\ Submitted Date: September $08^{\text {th }}, 2020$ \\ Revised Date: December 05 ${ }^{\text {th }}, 2020$ \\ Reviewed Date: September $28^{\text {th }}, 2020$ \\ Accepted Date: January $05^{\text {th }}, 2021$
}

\begin{abstract}
University Catur Insan Cendekia (UCIC) is a university located at Kesambi street number 202 Cirebon city. As one of the new universities in Cirebon city of course, would need inventory records of facilities and infrastructure that's what at the university. Additionally, records spending on facilities and infrastucture costs is important. To optimize that cost recording requires a system. To Improve management facilities and infrastructure requires data related to facilities conditions and infrastructure. Naïve's own method was the result of his prediction of the previous year's real data as a benchmark for forecasting the following year. The process of this method is to collect the data of the cost of facilities and infrastructure spending first, after which the system will predict the cost of facilities and infrastructure using the formula $N=t-1$, in addition to this web based research using the framework codeigniter. The forecast method conducted in the study using the naïve approach method, which is more effective than the moving average method. Nä̈ve's method was used to predict the cost data of facilities and infrastructure available at UCIC. The study also had the naïve approach prediction reached the following year's prediction.
\end{abstract}

Keywords: System; Forecasting; Nä̈ve; infrastructure; facilities

\begin{abstract}
Abstrak
Universitas Catur Insan Cendekia (UCIC) merupakan perguruan tinggi yang berlokasi di Jl. Kesambi No. 202 Kota Cirebon. Sebagai salah satu universitas baru di Kota Cirebon tentunya membutuhkan pencatatan data inventaris sarana dan prasarana yang ada pada kampus tersebut, selain itu juga pencatatan pengeluaran biaya sarana dan prasarana juga sangatlah penting. Untuk mengoptimalkan pencatatan biaya tersebut perlu dibuatkan suatu sistem. Untuk dapat meningkatkan manajemen sarana dan prasarana membutuhkan data-data sarana dan prasarana yang masih layak untuk dipakai atau tidak, Metode naüve sendiri memperoleh hasil prediksinya dari data real tahun sebelumnya yang menjadi patokan untuk melakukan proses peramalan pada tahun berikutnya. Proses metode ini adalah mengumpulkan terlebih dahulu data biaya pengeluaran sarana dan prasarana, setelah itu, sistem akan memprediksi peramalan biaya sarana dan prasarna dengan rumus $\mathrm{N}=\mathrm{t}-1$, selain itu juga penelitian ini berbasis web dengan menggunakan framework codeigniter. Metode peramalan yang dilakukan pada penelitian ini adalah menggunakan metode Nä̈ve Approach, metode ini dinilai lebih efektif dibandingan dengan metode moving average. Metode nä̈ve ini digunakan untuk meramalkan data biaya pengeluaran pengadaan sarana dan prasarana yang ada di kampus UCIC. Dalam penelitian ini juga sudah dapat menampilkan hasil prediksi dengan metode naïve approach pada peramalan tahun berikutnya.
\end{abstract}

Kata Kunci: Sistem; Peramalan; Nä̈ve; prasarana; Sarana

\section{Pendahuluan}

Sistem Inventaris pada kampus merupakan upaya untuk mengelola sarana prasarana kampus dan juga anggaran pengadaan sarana dan prasarana tersebut harus direncanakan secara matang. Untuk memaksimalkan biaya operasional untuk pengadaan sarana dan prasarana pada Universitas Catur Insan Cendekia digunakanlah 
metode peramalan(forecasting) untuk mengetahui perkiraan pengeluaran tahun berikutnya.

Untuk meningkatkan kualitas manajemen sarana dan prasarana membutuhkan data-data sarana dan prasarana yang masih layak untuk dipakai atau tidak, serta mencatat anggaran untuk pengadaan sarana dan prasana tersebut. Sementara itu di Universitas Catur Insan Cendekia pengolahan data sarana dan prasana dirasa belum dapat dioptimalkan kinerjanya.

Untuk mengatasi masalah tersebut, perlu adanya sistem yang mengatur data-data sarana dan prasarana secara teratur, selain itu juga diperlukan sistem yang dapat meramal biaya pengeluaran yang harus dikeluarkan Universitas CIC untuk pengadaan sarana dan prasarana yang ada, sehingga budget yang dikeluarkan lebih teratur lagi pengelolaannya.

\section{Metode Penelitian}

Pada penelitian ini penulis menerapkan prosedur penelitian menggunakan metode $S D L C$ (System Development Life Cycle). Pada penerapan metode ini penulis mempunyai 5 (lima) langkah yaitu Planning, Analysis, Design, Implementation, dan Maintenance (Nathasia \& Winarsih, 2019).

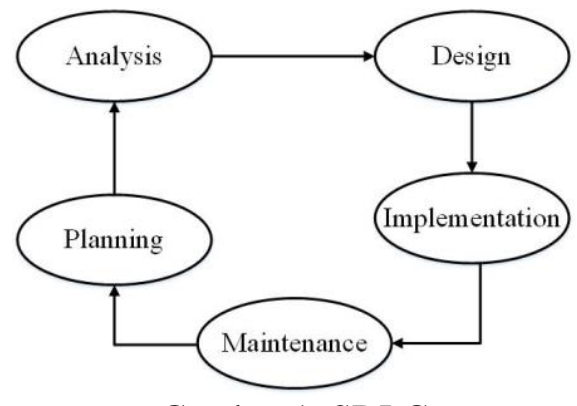

Gambar 1. SDLC

a. Planning

Pada tahap ini penulis mulai merencanakan sistem yang sesuai dengan tujuan dari penelitian ini. Mengidentifikasi masalah akankah dapatdiselesaikan dengan pengembangan sistem, selain itu menentukan prioritas teknologi yang akan digunakan dan pemilihan aplikasi.

b. Analysis

Pada tahap ini analis mencoba untuk menguraikan permasalahan sistem dan menggambarkannya kedalam beberapa diagram untuk menggambarkan situasi yang sedang berjalan, kemudian pada tahap ini analis mencoba mendesain sebuah solusi yang akan diberikan kepada user.

c. Design

Pada tahap ini penulis membuat rancangan diagram seperti use case, activity diagram, class diagram, sequence diagram, dan juga rancangan database yang akan dipakai pada sistem nantinya.

d. Implementation

Setelah membuat rancangan diagram, rancangan layouts dan juga rancangan database, penulis mencoba mengimplementasikan melalui coding, baik itu menggunakan $P H P$, maupun yang bahasa pemrograman yang lain. Pada tahap ini juga metode yang dipakai harus dimasukkan, pada penelitian ini penulis memakai metode Naive Approach.

e. Maintenance

Pada tahap ini adalah tahap untuk menjaga sistem agar tetap dapat beroprasi secara benar melalui kemampuan sistem dalam mengadaptasikan diri sesuai dengan kebutuhan. Serta memperbaiki bug yang terjadi pada sistem.

Sementara itu tahapan dari metode näve approach sendiri adalah :

a. Mendapatkan data pengadaan biaya sarana dan prasarana yang akan diolah dengan metode naïve approach.

Tabel 1. Data Biaya

\begin{tabular}{|c|c|c|c|c|}
\hline No & Unit Pengelola & \multicolumn{3}{|c|}{ Jenis Penggunaan } \\
\cline { 3 - 5 } & Program Studi & Biaya Sarana & Biaya Prasarana & Jumlah \\
\hline 1 & 2 & 3 & 4 & 5 \\
\hline 1 & 2015 & $\mathrm{Rp} .225 .000 .000$ & $\mathrm{Rp} .150 .000 .000$ & $\mathrm{Rp} .375 .000 .000$ \\
\hline 2 & 2016 & $\mathrm{Rp} .390 .000 .000$ & $\mathrm{Rp} .215 .000 .000$ & $\mathrm{Rp} .605 .000 .000$ \\
\hline 3 & 2017 & $\mathrm{Rp} .440 .000 .000$ & $\mathrm{Rp} .235 .000 .000$ & $\mathrm{Rp} .675 .000 .000$ \\
\hline 4 & 2018 & $\mathrm{Rp} .580 .000 .000$ & $\mathrm{Rp} .290 .000 .000$ & $\mathrm{Rp} .870 .000 .000$ \\
\hline 5 & 2019 & $\mathrm{Rp} .605 .000 .000$ & $\mathrm{Rp} .320 .000 .000$ & $\mathrm{Rp} .925 .000 .000$ \\
\hline 6 & 2020 & $\mathrm{Rp} .650 .000 .000$ & $\mathrm{Rp} .345 .000 .000$ & $\mathrm{Rp} .995 .000 .000$ \\
\hline
\end{tabular}


b. Menghitung Biaya Sarana dan Prasarana dengan metode Naive Approach.

Perhitungan peramalan biaya pengadaan sarana, sebagai berikut :

Rumus Naïve Approach adalah sebagai berikut : Naïve $\mathrm{t}=\mathrm{X}_{\mathrm{t}-1}$

Naïve $2015=2015-1$

$$
=\text { Rp. } 0
$$

Naïve $2016=2016-1$

$$
=\text { Rp. } 225.000 .000
$$

$$
\begin{aligned}
\text { Naïve } 2017 & =2017-1 \\
& =\text { Rp. } 390.000 .000 \\
\text { Naïve } 2018 & =2018-1 \\
& =\text { Rp. } 440.000 .000 \\
\text { Naïve } 2019 & =2019-1 \\
& =\text { Rp. } 580.000 .000 \\
\text { Naïve } 2020 & =2020-1 \\
& =\text { Rp. } 605.000 .000 \\
\text { Naïve } 2021 & =2021-1 \\
& =\text { Rp. } 650.000 .000
\end{aligned}
$$

Tabel 2. Hasil Peramalan

\begin{tabular}{|c|c|c|r|}
\hline No & Tahun(t) & Biaya sarana & \multicolumn{1}{l|}{ Hasil Peramalan } \\
\hline 1 & 2015 & Rp.225.000.000 & 0 \\
\hline 2 & 2016 & Rp.390.000.000 & Rp. 225.000.000 \\
\hline 3 & 2017 & Rp.440.000.000 & Rp. 390.000.000 \\
\hline 4 & 2018 & Rp.580.000.000 & Rp. 440.000.000 \\
\hline 5 & 2019 & Rp.605.000.000 & Rp. 580.000.000 \\
\hline 6 & 2020 & Rp.650.000.000 & Rp. 605.000.000 \\
\hline 7 & 2021 & - & Rp. 650.000.000 \\
\hline
\end{tabular}

\section{Pembahasan}

Analisis Sistem

Berikut merupakan Analisis Sitem Sistem

Forecasting sarana dan prasarana. c. Mendapatkan data pengadaan biaya sarana dan prasarana yang akan diolah dengan metode nä̈ve approach.

Tabel 1. Data Biaya

\begin{tabular}{|c|c|c|c|c|}
\hline \multirow{2}{*}{ No } & Unit Pengelola & \multicolumn{3}{|c|}{ Jenis Penggunaan } \\
\cline { 3 - 5 } & Program Studi & Biaya Sarana & Biaya Prasarana & Jumlah \\
\hline 1 & 2 & 3 & 4 & 5 \\
\hline 1 & 2015 & $\mathrm{Rp} .225 .000 .000$ & $\mathrm{Rp} .150 .000 .000$ & $\mathrm{Rp} .375 .000 .000$ \\
\hline 2 & 2016 & $\mathrm{Rp} .390 .000 .000$ & $\mathrm{Rp} .215 .000 .000$ & $\mathrm{Rp} .605 .000 .000$ \\
\hline 3 & 2017 & $\mathrm{Rp} .440 .000 .000$ & $\mathrm{Rp} .235 .000 .000$ & $\mathrm{Rp} .675 .000 .000$ \\
\hline 4 & 2018 & $\mathrm{Rp} .580 .000 .000$ & $\mathrm{Rp} .290 .000 .000$ & $\mathrm{Rp} .870 .000 .000$ \\
\hline 5 & 2019 & $\mathrm{Rp} .605 .000 .000$ & $\mathrm{Rp} .320 .000 .000$ & $\mathrm{Rp} .925 .000 .000$ \\
\hline 6 & 2020 & $\mathrm{Rp} .650 .000 .000$ & $\mathrm{Rp} .345 .000 .000$ & $\mathrm{Rp} .995 .000 .000$ \\
\hline
\end{tabular}

d. Menghitung Biaya Sarana dan Prasarana dengan metode Naive Approach.

Perhitungan peramalan biaya pengadaan sarana, sebagai berikut :

Rumus Naïve Approach adalah sebagai berikut :

Naïve $\mathrm{t}=\mathrm{X}_{\mathrm{t}-1}$

Naïve $2015=2015-1$

$$
=\text { Rp. } 0
$$

Naïve $2016=2016-1$

$$
=\text { Rp. } 225.000 .000
$$

Naïve $2017=2017-1$

$$
=\text { Rp. } 390.000 .000
$$

Naïve $2018=2018-1$

Naïve $2019=2019-1$

$$
=\text { Rp. } 580.000 .000
$$

Naïve $2020=2020-1$

$$
=\text { Rp. 605.000.000 }
$$

Naïve $2021=2021-1$

$$
=\text { Rp. 650.000.000 }
$$


Tabel 2. Hasil Peramalan

\begin{tabular}{|c|c|c|r|}
\hline No & Tahun(t) & Biaya sarana & Hasil Peramalan \\
\hline 1 & 2015 & Rp.225.000.000 & 0 \\
\hline 2 & 2016 & Rp.390.000.000 & Rp. 225.000.000 \\
\hline 3 & 2017 & Rp.440.000.000 & Rp. 390.000 .000 \\
\hline 4 & 2018 & Rp.580.000.000 & Rp. 440.000 .000 \\
\hline 5 & 2019 & Rp.605.000.000 & Rp. 580.000 .000 \\
\hline 6 & 2020 & Rp.650.000.000 & Rp. 605.000 .000 \\
\hline 7 & 2021 & - & Rp. 650.000 .000 \\
\hline
\end{tabular}

\section{Perencanaan Sistem}

Use Case Digram

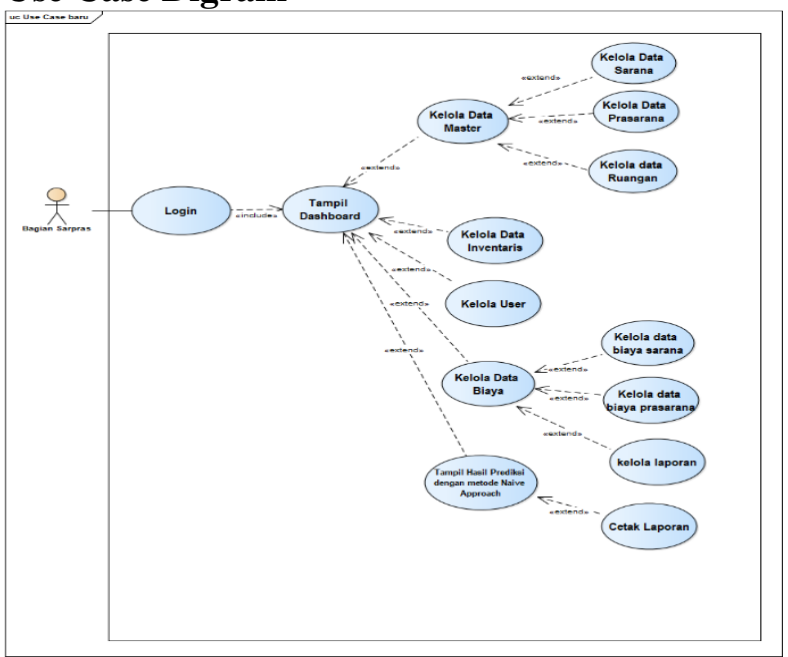

Gambar 2. Use Case Diagram

Keterangan Gambar 3 : Admin dalam hal ini bagian sarana dan prasarana akan melakukan login ke dalam sistem, setelah masu kedalam sistem

\section{Activity Diagram}

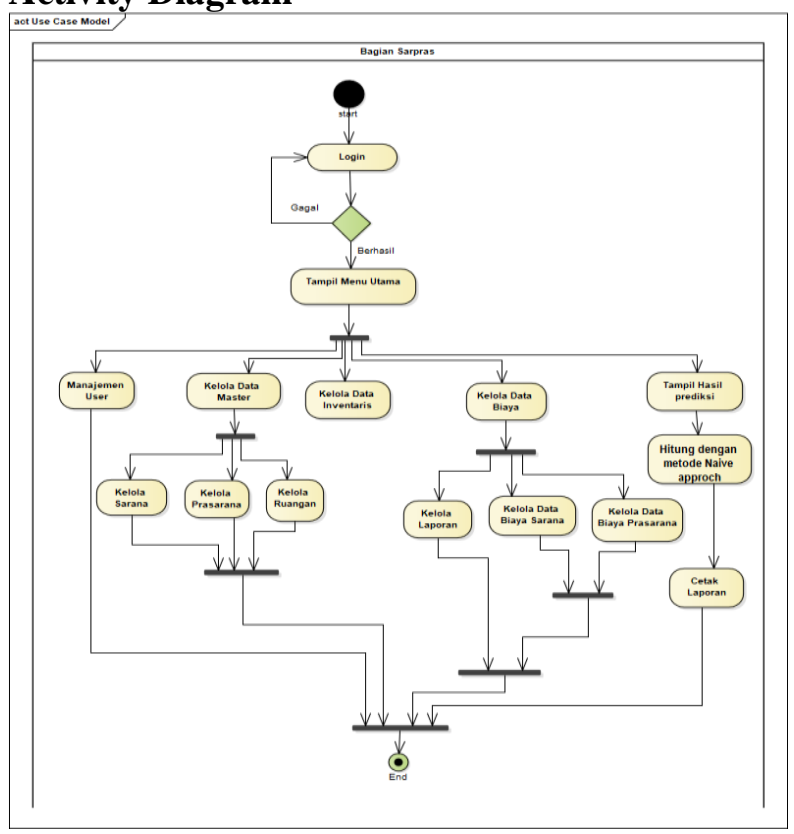

Gambar 3. Activity Diagram

\section{Imlementasi Sistem}

Setelah sistem dianalisis dan didesain secara rinci, maka akan menuju tahap implementasi. Implementasi merupakan tahap meletakkan sistem sehingga siap untuk dioperasikan. Implementasi bertujuan untuk mengkonfirmasi modul-modul perancangan, sehinga pengguna dapat memberikan masukan kepada pembangun

Sistem.

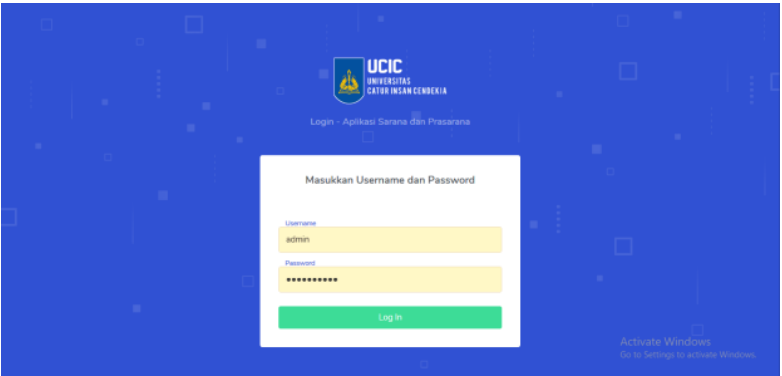

Gambar 4. Form Login

Setelah berhasil Login ke dalam sistem, seperti inilah halaman dashboard yang akan ditampilkan sebagai informasi hasil pengeluaran sarana dan prasarana.

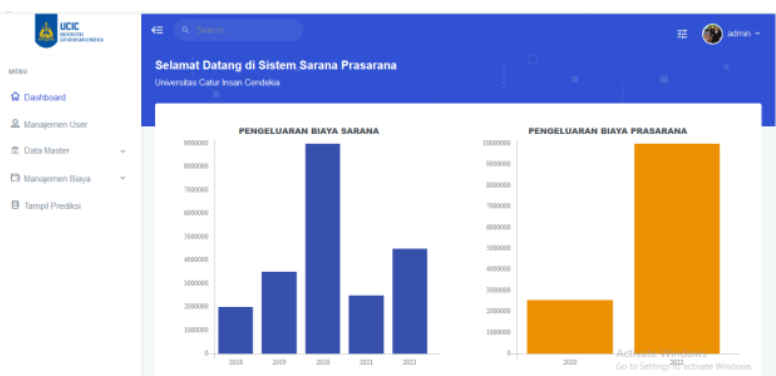

Gambar 5. Dashboard

Selanjutnya adalah halaman sarana, halaman ini berisikan data-data sarana yang ada di UCIC. Dengan variabel nama sarana dan kode sarana. 

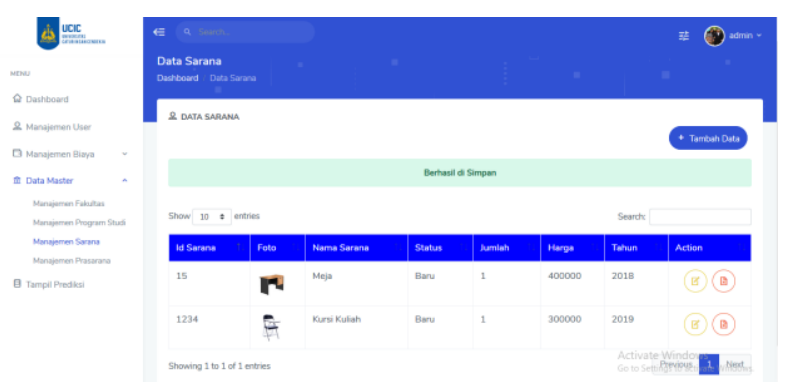

Gambar 6.Halaman Sarana

Setelah itu Sistem ini akan mecatat biaya pengeluaran sarana yang dibutuhkan untuk menghitung peramalan yang akan dilakukan.

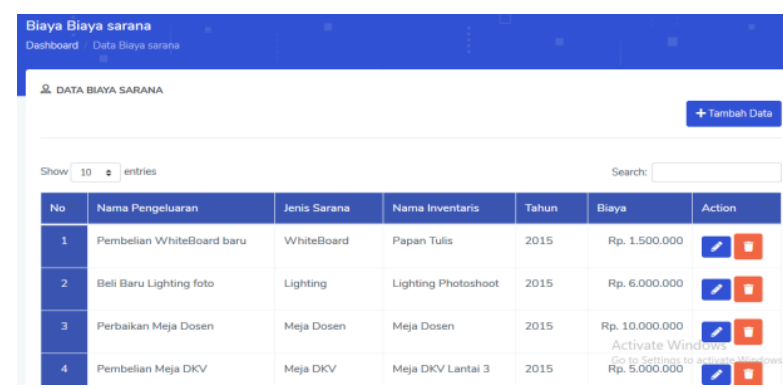

Gambar 7. Halaman Biaya Sarana

Setelah itu berikut merupakan halaman Prasarana untuk mendata prasarana yang ada pada kampus.

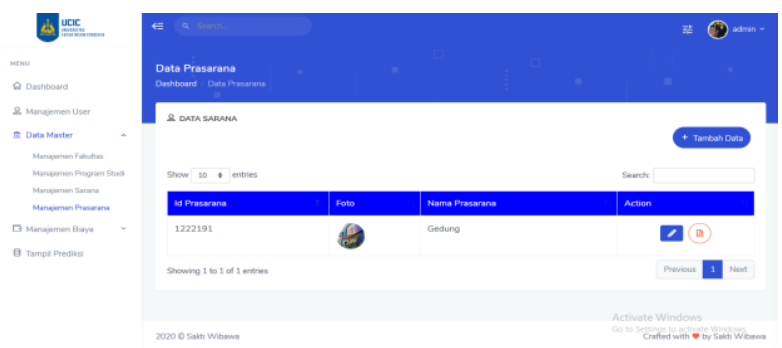

Gambar 8. Alaman Prasarana

Belanjutnya merupakan tabel biaya Prasarana yang digunakan per tahunnya.
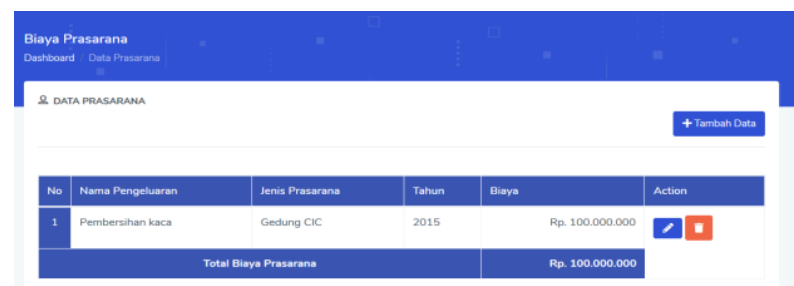

Gambar 9. Halaman Biaya Prasarana

Tahap selanjutnya adalah sistem menghitung hasil prediksi dan menampilkan hasil prediksi menggunakan metode naïve approach dengan rumus Naïve $\mathrm{t}=\mathrm{X}_{\mathrm{t}-1}$

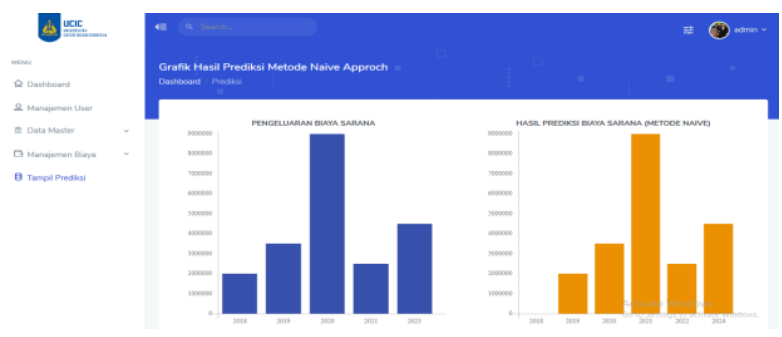

Gambar 10. Hasil Prediksi

Selain itu, pada penelitian ini juga dapat menginventaris barang pada UCIC, berikut adalah tampilan awal daftar inventaris per ruangan.

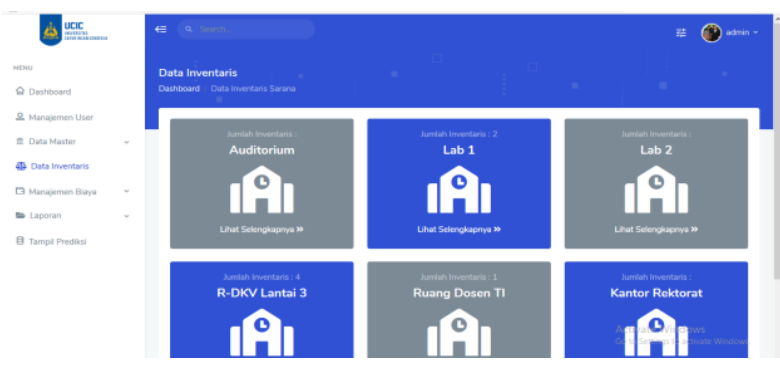

Gambar 11. Halaman Daftar Inventaris Ruangan

Selanjutnya admin dapat menambahkan barang inventaris sesuai dengan sarana yang ada pada tabel sarana.

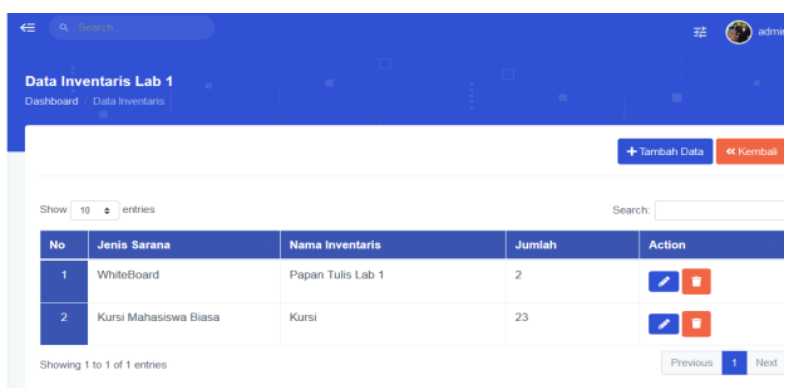

Gambar 12. Halaman Inventaris

\section{Kesimpulan}

Dari beberapa penjelasan yang telah diuraikan pada bab-bab sebelumnya, maka dapat disimpulkan beberapa hal sebagai berikut :

Telah dibuat Sistem Forecasting Sarana Dan Prasarana Dengan Metode Naive Approach pada UCIC.

Sistem tersebut diharapkan dapat membantu pengelola bagian keuangan agar dapat mengatur pegeluaran biaya sarana dan prasarana di UCIC. Dengan adanya sistem tersebut diharapkan pencatatan data sarana dan prasarana lebih maksimal. 
Adapun saran yang bisa dikembangkan pada aplikasi ini adalah Untuk pengembangan aplikasi selanjutnya aplikasi ini dapat lebih fleksibel lagi dan dapat diperbaharui lagi. Selain itu, tampilan grafik dari hasil peramalan dapat diperbaharui lagi agar dapat mempermudah pembacaan tabel.

\section{Referensi}

A. Suhendar, I. Novita, dan A. Ariesta, "Sistem Informasi Inventaris Barang Menggunakan Unified Modeling Language pada Kecamatan Gambir,” pp. 55-60, 2019.

V. R. Sutrisno, "Analisis Forecasting untuk Data Penjualan Menggunakan Metode Simple Moving Average dan Single Exponential Smoothing: Studi Kasus PT Guna Kemas Indah,” pp. 1-20, 2013.

M. Bakhar, "Sistem Informasi Inventaris Dan Perawatan Sarana Prasarana Di Politeknik Harapan Bersama," Jurnal Ilmiah Indonesia, No. 4, No.8, pp. 94-107, 2019.

S. U. Khasanah, A. D. Indriyanti, dan A. Danriani, "Sistem Peramalan Penjualan Tas Pada Toko Firdaus Bag Berbasis Web Menggunakan Metode Moving Average," INOVATE, No. 4, No. 2, pp. 28-36, 2020.

N. D. Nathasia dan U. Nasional, "Pengembangan System Video Gallery Hasil," Jurnal Informatika Merdeka Pasuruan, No. 4, No. 3, pp. 30-35, 2019.

M. R. Saputra dan S. Riyadi, "Sistem Informasi Populasi Dan Historikal Unit Alat-Alat Berat Pada Pt. Daya Kobelco Construction Machinery indonesia, " Jurnal Penelitian Dosen FIKOM (UNDA), No. 6, No. 2, pp. 1-6, 2019.

W. Wildaningsih dan A. Yulianeu, "Sistem Informasi Pengolahan Data Anggota Unit Kegiatan Mahasiswa (UKM) Zaradika Stmik Dci Tasikmalaya," Jurnal Manajemen dan Teknik Informatika, No. 2, No. 1, pp. 181-190, 2018.

S. D. Harahap. "Manajemen Sarana Dan Prasarana Untuk Efektivitas Layanan Administrasi Akademik Di Smk N.1 Tebing Tinggi." Skripsi S1, Universitas Islam Negeri Sumatera Utara, Medan, 2018.

A. Saputro et al., "Proceeding SINTAK 2019 ISBN : 978-602-8557-20-7 Proceeding SINTAK 2019 ISBN : 978-602-8557-20-7," Sintak 2019, vol. 3, no. 2017, pp. 402-410, 2019.

V. R. Sutrisno, "Analisis Forecasting untuk Data Penjualan Menggunakan Metode Simple Moving Average dan Single Exponential Smoothing: Studi Kasus PT Guna Kemas Indah,” pp. 1-20, 2013.

S. Rahayu, "Manajemen Sarana dan Prasarana Pendidikan," J. Isema Islam. Educ. Manag. , No. 4, No. 1, pp. 77-92, 2019.

M. V. Djabumir, A. Adib, A. Wijayanti, D. K. Visual, F. Seni, dan U. K. Petra, "Perancangan Website dan Media Pendukung Sebagai Promosi Suzanna Baby Shop Konsep Kreatif Metode Penelitian,' pp. 1-9, 2019.

M. S. Novendri, A. Saputra, dan C. E. Firman, "Aplikasi Inventaris Barang Pada Mts Nurul Islam Dumai Menggunakan Php Dan Mysql," Lentera Dumai, vol. 10, no. 2, pp. 46-57, 2019.

T. Hdanayani, Y. S. Bin Taher, A. H. Usman, dan A. Ambarita, "Aplikasi Pemeriksaan Biaya Instalasi Tegangan Listrik Rendah Berbasis Web Pada Pt. Ppiln Maluku Utara," IJIS - Indones. J. Inf. Syst., vol. 4, no. 1, pp. 32-40, 2019, doi: 10.36549/ijis.v4i1.51.

A. R. L. Francisco, "Konsep Dasar Sistem," J. Chem. Inf. Model., vol. 53, no. 9, pp. 1689-1699, 2019, doi: $10.1017 /$ CBO9781107415324.004.

E. Manurung dan P. S. hasugian, "Data Mining Tingkat Pesanan Inventaris Kantor Menggunakan Algoritma Apriori Pada Kepolisian Daerah Sumatera Utara," Journal Of Informatic Pelita Nusantara, No. 4, No. 2, 2019.

Fatimah dan Samsudin, "Perancangan Sistem Informasi E-Jurnal Pada Prodi Sistem Informasi Di Universitas Islam Indragiri," Jurnal Perangkat Lunak, No. 1, No. 1,pp. 332019.

D. Ambriani, "Rancang Bangun Repository Publikasi Ilmiah Dosen Berbasis Web Menggunakan Framework Laravel," Jurnal Manajemen Informatika, No. 10, No. 1, pp. 58-66, 2020.

S. S. Indasari. "Analisis Sistem Pengelolaan Data Alumni Jurusan Sistem Informasi Uin Alauddin Makassar Berbasis Web Menggunakan Framework Codeigniter." Skripsi S1, UIN ALAUDDIN MAKASSAR, Makassar, 2019.

Yunardi, A. A. Permana, "Rancang Bangun Sistem Informasi Keuangan Pada Pt. Secret Discoveries Travel Dan Leisure Berbasis Web," Jurnal Teknik Informatika Universitas Muhammadiyah Tangerang, pp. 1-7, 2018.

A. S. Rosa, M. Shalahuddin, "Rekayasa Perangkat Lunak Terstruktur Dan Berorientasi Objek,", 2015.

D. Valorino, W. Yustanti, "Rancang Bangun E-Voting Berbasis Web," Jurnal manajemen Informatika, No. 6, No. 2, pp. 1-9, 2016.

Verawati dan P. D. Liksha, "Aplikasi Akuntansi Pengolahan Data Jasa Service Pada PT. Budi Berlian Motor Lampung," Jurnal Sistem Informasi Akuntansi, No. 1, No. 1, pp. 1-14, 2018

A. Kumila, B. Sholihah, dan Evezia, "Perbandingan Metode Moving Average dan Metode Naïve Dalam Peramalan Data Kemiskinan," Jurnal Teori dan Aplikasi Matematika (JTAM), No. 3, No. 1, pp. $65-73,2019$. 